Revista Letras,

Curitiba, n. 94 jun./dez. 2016. ISSN 2236-0999

\title{
Arquifilologias do obscuro (ou quem conta história de dia cria rabo de cotia)
}

\author{
Archiphilologies of the obscure (or he who tells a story \\ by day grows a cotia tail) \\ Raul Antelo*
}

Resumo:

A razão cínica mascara-se como prática crítica na literatura contemporânea. Contra essa lógica, busca-se um novo tipo de filologia como rearranjo da velha e canônica disciplina, porque ela é o solo a partir do qual todas as ciências humanas tomam pé. A filologia repete as linguagens obscuras e impenetráveis.

Palavras-chave: Filologia, modernismo, arché.

ABstract:

Cynical reason masquerades itself as critical practice in contemporary literature. Against that logic, a new kind of Philology is required as an arrangement of the old canonical discipline, because it is the ground on which all humane studies finally take their stand. Philology is repetition of obscure and impenetrable languages.

Keywords: Philology, modernism, arché.

\footnotetext{
* Raúl Antelo (n. 1950) é professor titular de literatura brasileira na Universidade Federal de Santa Catarina. Pesquisador 1-A do CNPq, foi Guggenheim Fellow e professor visitante nas Universidades de Yale, Duke, Texas at Austin, Maryland, Autónoma de Barcelona e Leiden, entre outras. Presidiu a Associação Brasileira de Literatura Comparada (ABRALIC). É autor de vários livros, dentre os mais recentes, Maria com Marcel. Duchamp nos trópicos; Alfred Métraux: antropofagia y cultura; Imágenes de América e Archifilologías latinoamericanas. Lecturas tras el agotamiento.
} 
Antelo, R. Arquifilologias do obscuro

(ou quem conta história de dia cria rabo de cotia)
Revista Letras, Curitiba, n. 94 p. 12-24, jun./dez.
$\mathrm{S}$

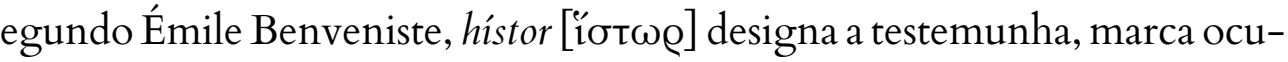
significa ver, e também a oida [oíioa], saber, compreender, porém sempre sob o ponto de vista de um conhecimento mediado pela constatação visual. Mas já para Tucídides, em A Guerra do Peloponeso, a tarefa já não se inclui mais na ordem da história testemunhal, mas na da inscrição: o verbo usado por Tucídides é suggra-

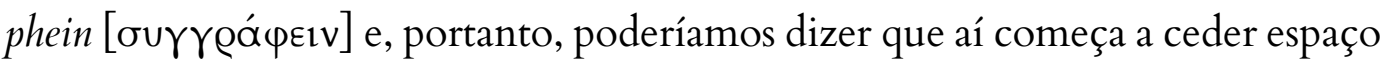

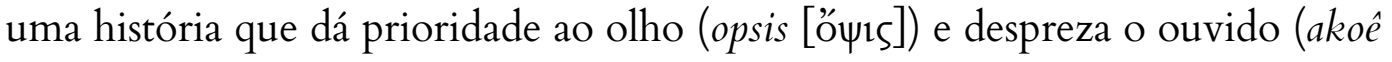
[’̊xón]). Giorgio Agamben, com efeito, corrobora essa leitura em Infânciae história ${ }^{1}$.

Mas mesmo tendo escrito uma História dos animais, Aristóteles curiosamente nunca usa o verbo historein. Por outro lado, aliás, é bem conhecida a passagem da Poética (1451a36-b11) em que o filósofo reserva à história a função de narrar fatos particulares que não garantem, contudo, o acesso ao saber científico, à autêntica episteme. Paradoxalmente, o século XIX, que recebe

1 "Come la parola che indica l'atto di conoscere (eidénai), cosí anche la parola historia deriva dalla radice id-, che significa vedere. Hístor è, in origine, il testimone oculare, colui che ha visto. La supremazia greca della vista trova anche qui la sua conferma. La determinazione dell'essere autentico come 'presenza allo sguardo' esclude un'esperienza della storia, che è ciò che è sempre già là senza mai essere sotto gli occhi come tale”. (AGAMBEN, 1978) 
Antelo, R. Arquifilologias do obscuro

(ou quem conta

história de dia cria rabo de cotia) essa tradição, processa-a de modo firme: a história avança e coloniza muitos campos do saber, da filologia à economia, e mesmo as novas ciências sociais. A rigor, o caráter científico desses campos consolida-se pari passu com a historicização de seus objetos. E, nesse sentido, como ciência piloto, a história passa a encarnar o progresso e a evolução, ideias mestras do século britânico por excelência, que colocavam a disciplina à altura da poesia ou da filosofia.

A posterior tradição crítica, de inspiração hegeliana, expressou-se através de Benedetto Croce (Teoria e storia della storiografia, 1912-3) e sua convicção de que toda história é história contemporânea; Robin Collingwood (The Idea of History, 1946) e sua reivindicação da autonomia histórica, que sempre lida com materiais intelectuais, porém nunca com fatos da natureza; ou Arnold Toynbee (A Study of History, 1934-61), que construiu uma história global, focando sempre, no entanto, o indivíduo. Nem Husserl nem Heidegger tiveram, contudo, muito impacto na historiografia posterior; e os ecos de Walter Benjamin e o caráter reversível entre cultura e barbárie, que ele enuncia em suas derradeiras Teses sobre filosofia da história, só muito recentemente puderam ser avaliados numa perspectiva que, seguindo os passos de Lacan, coloca, verso e reverso, Kant com Sade ${ }^{2}$.

Ora, Mário de Andrade nos fornece, numa passagem da carta às Icamiabas, um poderoso estímulo para entender a história não mais como aquilo que se vê, mas sim como aquilo que se ouve. A ideia sintoniza com a paradigmática frase que Oswald de Andrade escrevia no prefácio a Serafim Ponte Grande, abandonado nas páginas da Revista do Brasil, em 1926: a gente nunca escreve o que houve e sim o que ouve. Nesse sentido, lemos em Macunaíma uma observação sobre a linguagem dos habitantes de São Paulo que encerra toda uma teoria da literatura por vir.

Ora sabereis que a sua riqueza de expressão intelectual é tão prodigiosa, que falam numa língua e escrevem noutra. Assim chegado a estas plagas hospitalares, nos demos ao trabalho de bem nos inteirarmos da etnologia da terra, e dentre muita surpresa e assombro que se nos deparou, por certo não foi das menores tal originalidade lingüística. Nas conversas utilizamse os paulistanos dum linguajar bárbaro e multifário, crasso de feição e impuro na vernaculidade, mas que não deixa de ter o seu sabor e força nas apóstrofes, e também nas vozes do brincar. Destas e daquelas nos inteiramos, solícito; e nos será grata empresa vo-las ensinarmos aí chegado. Mas si de tal desprezível língua se utilizam na conversação os naturais desta terra, logo que tomam da pena, se despojam de tanta asperidade, e

2 A bibliografia sobre o tópico é muito vasta. Destaco, entretanto, ARENDT, 1997; BENJAMIN, 2008; Idem, 2006; BURCKHARDT, 2015; CASSIN, 1995; CERTEAU, 1975; CHARTIER, 1998; FEBVRE, 1965; GINZBURG, 1989; HARTOG, 1999; KOSELLECK, 2004; LACAN, 1998,; NIETZSCHE, 2005; RICEUR, 2000. SCHEID-TISSINIER, 1994; TRAVERSO, 2011; WHITE, 1992.
Revista Letras, Curitiba, n. 94 p. 12-24, jun./dez. 
Antelo, R.

Arquifilologias do obscuro

(ou quem conta

história de dia cria rabo de cotia) surge o Homem Latino, de Lineu, exprimindo-se numa outra linguagem, mui próxima da vergiliana, no dizer dum panegirista, meigo idioma, que, com imperecível galhardia, se intitula: língua de Camões! De tal originalidade e riqueza vos há de ser grato ter ciência, e mais ainda vos espantareis com saberdes, que à grande e quase total maioria, nem essas duas línguas bastam, senão que se enriquecem do mais lídimo italiano, por mais musical e gracioso, e que por todos os recantos da urbs é versado. De tudo nos inteiramos satisfatoriamente, graças aos deuses; e muitas horas hemos ganho, discretando sobre o z do termo Brazil e a questão do pronome "se". Outrossim, hemos adquirido muitos livros bilíngües, chamados "burros", e o dicionário Pequeno Larousse; e já estamos em condições de citarmos no original latino muitas frases célebres dos filósofos e os testículos da Bíblia³ (ANDrade, 1996).

O humor nasce precisamente de uma filologia praticada pelo avesso. Porque se o historiador é testis, testemunha ocular, é também desse significante, testis, que deriva a gênese e a reprodução sexual, os testículos da Bíblia ${ }^{4}$. Mas observe-se que Mário de Andrade recria, então, como destinatárias ficcionais desse relato paródico, as Icamiabas ou Amazonas, cujo mito tem origem nos escritos de Bachofen sobre o matriarcado (BACHOFEN, 1987)5. Lembremos, a propósito, que Bachofen baseou-se, por sua vez, na lenda de Belerofonte e a vitória de Teseu sobre Antíope (Illiada III, 189), uma das mais antigas histórias do mundo helênico, que assim se lê, na língua de Camões, na versão de Odorico Mendes:

Pasma e exclama o ancião: "Feliz Atrida!

Mimoso da fortuna, que em florentes

3 A seguir, Mário suprime um fragmento em que Macunaíma observa que os brasileiros são oradores natos, "pronunciando com facilidade graciosa de dicção e rara eloqüência, o aluvião de palavras que lhes brotam, enternecedoras dos lábios".

4 FOnSECA, Maria Augusta - "A carta pras Icamiabas" in andrade, Mário de - Macunaíma: o herói sem nenhum caráter, op.cit., p. 329-345.

5 Engels (1974), no prefácio de 1891 à quarta edição de $A$ Origem da família, da propriedade privada e do Estado, resgata a descoberta de Bachofen, argumentando que, primitivamente, só se podia contar a descendência através de uma linhagem feminina, mas que essa situação arcaica das mães, como os únicos genitores certos de seus filhos, assegurou a elas a posição social mais elevada que tiveram. A passagem do "heterismo" à monogamia e do direito materno ao paterno se produz, entre os gregos, como conseqüência do desenvolvimento das novas ideias religiosas, como efeito da introdução de novas divindades, que equivalem a novas representações, no grupo dos deuses tradicionais, mera encarnação dos velhos valores. Aos poucos, os antigos deuses são jogados ao escanteio pelos mais novos e Bachofen conclui que não foi o desenvolvimento das reais condições de existência dos homens, mas o reflexo religioso dessas condições, o que determinou as mudanças históricas na situação social recíproca do homem e da mulher. Consequentemente, Bachofen interpreta, da mesma maneira que o fará, no século xx, Pasolini, que a Orestíada de Esquilo é o autêntico quadro dramático da luta entre o direito materno agonizante e o direito paterno ascendente, que se formou sobre aquele, na época das epopeias. Bachofen, mesmo sem ter enunciado esses princípios dialéticos com clareza, produziu, porém, em 1861, uma autêntica revolução teórica que Engels capitalizaria mais adiante para sua teoria do Estado.
Revista Letras, Curitiba, n. 94 p. 12-24, jun./dez. 
Antelo, R.

Arquifilologias do obscuro

(ou quem conta

história de dia cria rabo de cotia)
Graios dominas! Muitos vi peritos

Cavaleiros na Frigia pampinosa,

$\mathrm{E}$ as de Migdon divino e Otreu falanges,

Que do Sangário às bordas acampavam;

Lá como auxiliar no ataque estive

Das viris Amazonas: mor quantia

De olhinegros Aquivos se apresentam.

Mas as Amazonas não são apenas helênicas. Da mesma forma, na Índia, a lenda de Raná-Paramitá, no Mahabarata, em que as mulheres moram de um lado do rio, enquanto os homens habitam a outra margem, encontra apoio também, na cultura chinesa, na história de Ta-tang-hsi-yu-chi. Em todo caso, a fonte medieval mais citada na Europa para provar a existência das Amazonas é a tradução das viagens de Alexandre Magno (Itinerarium Alexandrii), realizada por Flavius Iulius Valerius Alexander Polemius, no século IV da nossa era, que aliás deve ter inspirado, entre outros, a Benoît de St. Maure, autor que já alude ao pais de Amazoine no Roman de Troie:

\footnotetext{
Ço nos recontent li Traitié

E li grant Livre Historial,

Qu'en la partie Oriental

Est Amazoine, terre grant :

Oez que nos trovons lisant.

De femmes est tote habitée
}

Além do Roman de Troie, Marco Polo cita também o mito das mulheres guerreiras. A viagem é aí uma metáfora; mas a metáfora é, precisamente, um transporte através da linguagem. Em todo caso, a lenda das Amazonas conecta-se ainda com a dos cinocéfalos e os pigmeus, entendidos como écarts de la nature, como diria Bataille, para quem a teratologia integra, decididamente, a estética (ROSENTHAL, 1937; BATAILle, 1930). Em outras palavras, a arte moderna, inscrita no plano da história, desvia-se completamente, e de forma definitiva, da natureza. A propósito, em 1924, um pequeno texto anônimo, que podemos sem dúvida atribuir ao poeta Oliverio Girondo, uma vez que menciona a coleção do Museu Capitolino de Roma, por ele visitado pouco antes e registrado em um caderno de viagem (ANTElo, 1999), funciona como epígrafe de uma imensa foto do cinocéfalo, com uma citação de Voronoff, presente também no Manifesto Antropófago, e usada, em ambos os casos, como via para o retorno da experiência perdida.

La simpática y culta boga que nos han traído los descu- 
Antelo, R.

Arquifilologias do obscuro

(ou quem conta

história de dia cria rabo de cotia) brimientos de Lord Carnavón, hace interesante cuanto se refiere a Egipto. He aquí el cinocéfalo, mono de perruna cabeza, que fue adorado por los egipcios al par de numerosos animales. Esta efigie zoolátrica, que se guarda en el Museo Capitolino de Roma, proviene del templo de Isis, diosa de la fecundidad. Todos cuantos buscan una razón práctica a las divinidades egipcias, afirman que, por ejemplo, el cocodrilo era adorado porque entre las primeras aguas de la inundación bienhechora del Nilo venían envueltos ejemplares de ese reptil. Y como, según afirmaba Edgardo Poe, los egipcios lo sabían todo, ¿no hay derecho a lanzar la afirmación de que hubo en Tebas o en Menfis un cirujano benéfico, precursor de Voronoff? Así podría explicarse el porqué se adoraba al cinocéfalo, portador de glándulas rejuvenecedoras como el chimpancé de nuestros días. El agradecimiento de los Faraones, sacerdotes, escribas y millonarios juvenilmente reformados se tradujo en estatuas y oraciones. ${ }^{6}$

Cortar, enxertar, escrever, todas operações de gerar o novo. Ora, vinculado ao ciclo das Amazonas, temos ainda a figura de Jurupari, que pela antiga lei da convergência, tem muitas das suas peripécias assimiladas ao Poronominare dos barés e ao Macunaima do Orinoco, ciclos míticos que cedem muitos temas para Jurupari, líder de uma sociedade toda feminina, sobre a qual pesava o interdito de não tocarem flautas. Luiz da Câmara Cascudo assim nos esclarece:

Instrumentos sagrados do culto de Juruparí parecem uma característica. São tidos como tabus. Juruparí é dado como “deus musical”, "deus dos sons”. Alfred Rusell Wallace dizia-o "devil music". Só os homens iniciados podem ouvir e tocar. A mulher que lhes entender o som está condenada à morte pelo veneno, e sendo homem não-iniciado, morrerá a golpes de tacapes, cuidarú e bordunas. [...] Parece que nem todos esses instrumentos foram usados. A crônica indígena e as lendas se referem sempre a duas espécies de trombetas, feitas de madeira, quase sempre pachiuba, passiva (Iriartéa exorrhiza, Martius) com 30, 50, $70 \mathrm{~cm}$. e mais de metro de comprimento, dando um som cavo e profundo. Essa música surgida no negror da floresta é inesquecível e penetrante. Liga-se indelevelmente ao culto de Juruparí. Dão a esse instrumento o nome de "Juruparí".

'On donne encore le nom de Jurupary à divers instruments de

6 "Cuarenta siglos antes de Voronoff". Plus Ultra, Buenos Aires, n ${ }^{\circ}$ 94, fev. 1924, p.11. 
Antelo, R. Arquifilologias do obscuro

(ou quem conta

história de dia cria rabo de cotia) musique, et particulièrement à une especie de longue trompette faite de pachiuba'. Sant'Ana Neri : - Folklore Brésilien. Perrin - pág. 244. Paris - 1889.

Mario Melo descreve o instrumental dos Carijós (Fulniôs) de Aguas Belas (Pernambuco): - ... "Uma espécie de tuba de um metro ou mais de comprimento, a que chamam iakitxá. De diâmetros diferentes, a mais grossa, no diapasão de contrabaixo, serve para a marcação nos primeiros tempos do compasso, enquanto a outra, adequada à escala de barítono, faz o papel de trombone no acompanhamento, em notas mínimas, sempre as mesmas, que os instrumentos não permitem mais de uma”. É um tabu como o aidje dos Borôros, que Karl von den Steinen chama Schwirrholz.

Nem olhavam as mulheres para tais cabanas; e este costume se manteve. Nesses verdadeiros templos parecís '(Iamaká) não mais residem os ídolos do século XVIII; guardam-se neles os instrumentos sagrados da tribu, cada qual filiado em uma função exorcística. Hoje, porém, como outrora, as mulheres se livram de olhar a Iamaká. Minhas canastras, onde, muito em segredo, eram conduzidos os instrumentos de musica das coleções, conseguidas, mercê do prestigio de Rondon, para o Museu Nacional; durante todo o tempo em que estiveram em territorio parecí mereceram o mesmo respeito. De Utiarití, onde eu as obtive, até Aldeia Queimada, último ponto onde encontrei na volta, índios dessa tribu, sofreu minha bagagem vigilância apurada, para impedir que alguma pobre mulher visse as santas avenas. Morre a mulher que põe os olhos em tais buzinas; e, se não morre, arranjam sempre os sacerdotes do seu rito modos para que morra. (CASCUDo, 1942, p. 160-175).

Para além da conexão entre Jurupari e Macunaíma (MEDEIRos, 2002), apontada por Câmara Cascudo, caberia ainda lembrar, a propósito, que, com assombro idêntico ao do herói-sem-nenhum-caráter, Jacques Lacan definia a tarefa do analista como uma histoeria (hystoire), cujo objetivo consistiria em hystoristerizar (hystoriser) a si mesmo, oferecendo sua análise como algo "um pouco parecido à anedota” (LACAN, 2003), fórmula coincidente, aliás, com a de Guimarães Rosa em Tutameia.

Ora, na ficção contemporânea, poderíamos dizer que um dos movimentos mais notáveis da escritura de César Aira consiste, precisamente, em se hystoriser, ou seja, hystoristerizar-se a si próprio. Aira não escreve a partir da memória, mas se instala, decididamente, no esquecimento. "Acabou-se a história e morreu a vitória”. Ou como diriam os tupis: U mumbán tekó poranga... Acabou-se a vida bonita. Entre a memória obsessiva da tradição, que só se interessa em preservar
Revista Letras, Curitiba, n. 94 p. 12-24, jun./dez. 
Antelo, R. Arquifilologias do obscuro

(ou quem conta

história de dia cria rabo de cotia)

"a língua de Camões”, e o desembaraço do esquecimento, que se entrega ao inexistente, o novo texto tem a estrutura do arquivo, um "ainda-não-dito", um inaudito, que está inscrito em tudo o que se disse pelo simples fato de ter sido enunciado, mesmo de forma aturdita; ou seja, ele é um fragmento de memória que paradoxalmente se oblitera a cada vez que se ativa. O esquecimento, em suma, funcionaria então como a forma mais sofisticada de recriar a ficção.

Mas, além de vedada, como no mito indígena originário, a trombeta contemporânea mimetizou-se com o receptáculo, a cesta de vime. E uma trombeta de vime não é só tabu: ela é um objeto impossível, de tal sorte que as Amazonas, em suma, podem ser vistas, admiradas, perversamente desejadas, mas elas não ouvem, nem tocam as tais trombetas, portanto, elas não são ouvidas. A elas narra-se o que houve, e não o que se ouve. Mas é óbvio também que ninguém poderia executar as tais trombetas de vime, portanto, todos somos Amazonas. Hystoristerização disseminada dos leitores, em suma.

La memoria es el planeta en el que vive la lectura, así que no puede extrañar que haya empezado con ella, y vaya a terminar con ella, escalando los peldaños de una complejización que soy el primero en deplorar. Porque yo soy el evangelista de la simplificación, en la que pongo todas mis esperanzas. Y es por eso que soy tan decidido enemigo de la memoria, ese barroquismo: si por mí fuera, no la usaría nunca, y como eso no es posible, al menos querría despojarla de todo su ropaje, de su hojarasca, de su "poesía", y dejarla reducida a una pura mnemotecnia, a la máquina que la realice y la aniquile al mismo tiempo. Esta guerra unipersonal sólo puede llevarse a cabo en el terreno de la literatura, y la batalla final debería ser la creación de un mito de origen de la memoria. Pero es utópico, irrealizable. La memoria es la profecía autocumplida por excelencia (como la Narapoia), y quizás la simplificación debería empezar por una inversión, que hiciera de la memoria la "momeria".

(AIRA, 1998, p. 41)

O escritor torna-se então um mímico dadá, diria Hal Foster: Artaud, le moma, acrescentaria Derrida (2002).

Hacer copias de lo que uno escribe no es sólo prudencia: también es libertad. Uno puede trasladarse, sin equipaje, en busca de aventuras que serán la fuente de inspiración para futuros libros, sin preocuparse por lo que queda atrás, porque en cierto modo atrás no queda nada; las copias permanecen ocultas, 
Antelo, R.

Arquifilologias do obscuro

(ou quem conta

história de dia cria rabo de cotia) como tesoros, ocultas en su propia reproducción mecánica. Además, a eso tiende naturalmente lo escrito: al libro, que es una copia: un libro impreso es la copia que recupera su condición de original, con todas las idiosincrasias, las extravagancias, las rarezas a veces inconcebibles de lo único. Y no importa que se destruya, porque se reconstituye en otro ejemplar.

(Idem, p. 29)

Essa mímica dos intercâmbios, mediada pelo significante clássico, o dinheiro, é outra forma de dizer que a hystoeria manda trocar a ordem significante daquilo que poderia ser um mito originário para ver o que se escreve a partir daquilo que ficou esquecido por trás do que se disse naquilo que se ouve. Aira, então, nos dá os elementos do mito de origem da Narapoia:

Se trataba de un psicoanalista, que recibía a un paciente nuevo y lo escuchaba. El problema del paciente era de tipo persecutorio, una pesadilla en la vigilia, la sensación constante de estar participando de una pesquisa o vigilancia, en las calles, y la sospecha sobre la realidad de lo que estaba pasando... No se explicaba bien, sus frases eran ambiguas, pero la idea general del asunto, sumada a su aspecto perturbado, ansioso, configuraban un caso clásico de delirio persecutorio, y el analista no tardaba en iniciar la interpretación; lo hacía con todo el aburrimiento de encontrarse una vez más ante un caso "de manual", de los que tenía tres por semana y demostraban que la patología de la mente ya estaba tan trillada, tan cartografiada... "Usted sufre de un mal muy conocido, que se llama paranoia...", y procedía a repetir de memoria los síntomas. El paciente lo interrumpía: "No, usted me entendió mal. No es la sensación de ser perseguido la que me tortura, sino la de estar persiguiendo a alguien”. ¡Epa! El analista daba un respingo, se despertaba de su siesta rutinaria. Esto era muy interesante. Y no sólo para salvar del tedio una tarde de neuróticos. Porque estaba seguro de que esta sintomatología no estaba registrada en la bibliografía analítica, que él conocía bien. Este hombre padecía de una enfermedad nueva, y el azar lo había traído a su consultorio, dándole la oportunidad única de hacer la primera descripción, la canónica, y asegurarse un lugar en la historia de la psiquiatría. Era un privilegio que no iba a desaprovechar. Su carrera, estancada en una práctica mediocre y sin horizontes, podía tomar de aquí en más un camino estelar. Tomaba nota de cada palabra del paciente, le hacía preguntas, y al final 
Antelo, R.

Arquifilologias do obscuro

(ou quem conta

história de dia cria rabo de cotia) de la sesión le daba cita para el día siguiente. Esa noche pasaba en limpio sus notas, empezaba a hacer hipótesis, esbozaba los primeros párrafos del artículo en que daría a conocer su descubrimiento, se dejaba llevar en proyectos de ponencias de congresos, un libro... Entre sus privilegios de descubridor estaba el de darle un nombre a esta nueva patología, y como era lo mismo que la paranoia pero al revés, decidía bautizarla "Narapoia".

(AIRA, 1998, p. 36-37)

Na conclusão de seu ensaio sobre a passagem do livro à tela, ou seja, no trânsito do pré- ao pós-letrado, Giorgio Agamben nos propõe uma peculiar definição de pensamento:

Pensare significa ricordarsi della pagina bianca mentre si scrive o si legge. Pensare - ma anche leggere - significa ricordarsi della materia. E come i libri di Manganelli e di Mallarmé non erano forse altro che un tentativo di riportare il libro alla pura materialità della pagina bianca, cosí chi usa un computer dovrebbe essere capace di neutralizzarne la finzione di immaterialità, che nasce dal fatto che lo schermo, l'"ostacolo" materiale, il senza forma di cui tutte le forme non sono che la traccia, gli resta ostinatamente invisibile. (AGAMBEN, 2014, p. 111-112)

De maneira coincidente, no final de $A$ trombeta de vime, César Aira também profetiza uma nova forma de leitura: a de resgatar as marcas do que nunca foi escrito. Isso inclui, claro está, os desvios da natureza, o ouvido cortando e montando aleatoriamente os significantes que fazem parte da cultura e concedendo assim peculiar materialidade a uma escrita que se torna imaterial a cada novo lance da história. Nesse sentido, a arquifilologia funcionaria como uma autêntica mitologia crítica pós-fundacional, que sem cessar reabre nossa compreensão dos caminhos compartilhados por ficção e história.

En este punto hay que preguntarse: ¿con qué se hacen los libros? Salvo que la pregunta debería ser: ¿con qué no se hacen? Todo resulta apropiado a la larga; cualquier tema, cualquier intención, cualquier actitud. Todos los libros son libros, pero todos son distintos porque han abrevado en las innumerables posturas de la vida social del hombre. Lo siguen y seguirán haciendo, en tanto existan hombres y libros. No hay que preocuparse por la originalidad porque sería virtualmente imposible que no la haya. Es como si el libro hubiera sido siem- 
Antelo, R. Arquifilologias do obscuro

(ou quem conta história de dia cria rabo de cotia) pre un objeto experimental, la prueba infinitamente renovada de una particularidad absoluta. Un libro cualquiera puede ser modelo de todos los demás: de ahí que sea urgente establecer una tipología y al mismo tiempo no sea urgente ni tenga la menor importancia. Los "tipos" de libro se extienden en todas direcciones y a través de todos los niveles: novelas, catálogos, epistolarios, manuales, ilustrados, de tapa dura, de veinte páginas, de mil setecientas, apasionantes, para niños, de poesía, de viajes, best sellers, técnicos, troquelados, clásicos, en chino, en papel de arroz... Al ponerse al alcance de todos, esta multiplicidad exige formas nuevas de erudición, tan nuevas que no podemos imaginarlas y que sin embargo ya están en funcionamento. (AIRA, 1998, p. 132) 
Antelo, R. Arquifilologias do obscuro

(ou quem conta história de dia cria rabo de cotia)

\section{Referências}

AGAMBEN, Giorgio. "Dal libro allo schermo. Il prima e il dopo del libro" in Il fuoco e il racconto. Roma, nottetempo, 2014, p.111-2

AIRA, César. La trompeta de mimbre. Rosario, Beatriz Viterbo Editora, 1998, p. 41

ANDRADE, Mário de. Macunaíma: o herói sem nenhum caráter. $2^{\mathrm{a}}$ ed. Ed. crítica Telê Porto Ancona Lopez. Madrid - Paris, Archives de la littérature latino-américaine, des Caraïbes et africaine du XXe, 1996, p. 84 (Coleção Arquivos, vol. 6).

ANTELO, Raul. "Estudio filológico" in GIRONDO, Oliverio - Obra Completa. Madrid, ALLCA XX, 1999, p. XXVII-XC

ARENDT, Hannah . "O Conceito de História. Antigo e Moderno" in Entre o passado e o futuro. 4. ed. São Paulo, Perspectiva, 1997

BACHOFEN, Johann Jakob. El matriarcado. Trad. María del Mar Llinares García. Madrid. Akal, 1987

BATAILLE, Georges - «Les écarts de la nature». Documents, nº 2, Paris, nov. 1930, p. 79.

BENJAMIN, Walter. "Teses sobre o conceito o História" in Obras escolhidas. Magia e técnica; arte e política. São Paulo, Brasiliense, 2008, p.222-231;

. Passagens. Belo Horizonte, Editora UFMG, São Paulo, Imprensa Oficial do Estado de São Paulo 2006

BURCKHARDT, Jacob. Reflexões sobre a História. Rio de Janeiro, Zahar, 1961

CARERI, Giovanni e DIDI-HUBERMAn, George. L'histoire de l'art depuis Walter Benjamin. Paris, Mimésis, 2015

CASCUDO, Luiz da Câmara. "Jurupari”. Cultura Política, a. 2, n 19, Rio de Janeiro, set. 1942, p. $160-175$.

CASSIN, Barbara. L'effet sophistique. Paris, Gallimard, 1995

CERTEAU, Michel de. L'ecriture de l'histoire. Paris, Gallimard, 1975

CHARTIER, Roger. Au bord de la falaise: L'histoire entre certitudes et inquietude. Paris, Michel, 1998

DERRIDA, Jacques. Artaud le Moma: interjections d'appel. Paris, Galilée, 2002

ENGELS, Friedrich. A Origem da família, da propriedade privada e do Estado. Rio de Janeiro, Civilização Brasileira, 1974

FEBVRE, Lucien. Combats pour l'histoire. Paris, Armand Colin, 1965

FONSECA, Maria Augusta. "A carta pras Icamiabas" in ANDRADE, Mário
Revista Letras, Curitiba, n. 94 p. 12-24, jun./dez. 
Antelo, R. Arquifilologias do obscuro

(ou quem conta história de dia cria rabo de cotia)

de - Macunaíma: o herói sem nenhum caráter, op.cit., p. 329-345

FOSTER, Hal. "Dada mime" in October, n ${ }^{\circ}$ 105, Verão de 2003, p. 166-176. Há tradução de Larissa C. da Mata no Boletim do NELIC: https://periodicos. ufsc.br/index.php/nelic/article/viewFile/1984-784X.2012v12n17p96/24219.

GINZBURG, Carlo. Mitos, emblemas e sinais: Morfologia e História. São Paulo, Cia. das Letras, 1989

HARTOG, Francois. L'histoire d'Homere a Augustin. Paris, Seuil, 1999

KOSELLECK, Reinhart. Futures Past: On the Semantics of Historical Time. Trad. Keith Tribe. New York, Columbia University Press, 2004

LACAN, Jacques. "Kant com Sade". Escritos. Trad. Vera Ribeiro. Rio de Janeiro, Jorge Zahar, 1998, p.776-803

"Prefácio à edição inglesa do Seminário 11" in Outros Escritos.

Rio de Janeiro, Jorge Zahar Editor, 2003, p. 567-8.

MEDEIROS, Sérgio (ed.). Makunaíma e Jurupari. Cosmogonias ameríndias. São Paulo, Perspectiva, 2002.

NIETZSCHE, Friedrich. "Sobre a utilidade e desvantagens da História para a Vida" in Escritos sobre a História. São Paulo, Loyola, 2005

RICCEUR, Paul. La memoire, l'histoire, l'oubli. Paris, Seuil, 2000

ROSENTHAL, Albrecht. "The isle of the Amazons". The Journal of the Warburg and Coultard Institutes, vol I, 1937, p. $257-259$

SCHEID-TISSINER, Evelyne . "A propos du role et de la fonction de l'histor." Revue de Philologie, $\mathrm{n}^{\circ}$ 68,1994, p. 187-208

TRAVERSO, Enzo. L'histoire comme champ de bataille. Interpréter les violences du xxe siècle, Paris, La Découverte, Paris, 2011

WHITE, Hayden. A Meta-História - a Imaginação Histórica no século XIX. São Paulo, EDUSP, 1992

Submetido em 16/9/2016

Aceito em 24/9/2016 